\title{
Civilizar para consumir: as favelas e os processos civilizatórios no documentário seriado No reservations*
}

CiVILIZE tO CONSUME: SLUMS AND CIVILIZING PROCESSES IN THE DOCUMENTARY SERIES

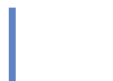

\section{Ricardo Ferreira Freitas}

Professor associado do Programa de Pós-Graduação em Comunicação da Universidade do Estado do Rio de Janeiro (UERJ). Doutor em Sociologia pela Sorbonne.

rf0360@gmail.com

\section{Ana Teresa Gotardo}

Doutoranda em Comunicação pela Universidade do Estado do Rio de Janeiro (UERJ). aninhate@gmail.com

\section{Resumo}

Este artigo aborda os imaginários em torno das favelas da cidade do Rio de Janeiro no documentário seriado sobre turismo No Reservations, de Anthony Bourdain. Por meio de uma análise crítica, percebe-se que o episódio apresenta as UPPs e as oportunidades no esporte, mais especificamente no Jiu-Jitsu, como formas de alcançar uma vida mais "digna" e "desejada" - ou, sob outra perspectiva, como processos civilizadores, dentro de um contexto no qual a favela se tornaum produto a ser consumido, enquanto novo destino turístico da "cidade dividida".

Palavras-chave: Imaginários. Cidade. Consumo.

* Este artigo foi desenvolvido com base no texto "As favelas e as construções de processos civilizatórios modernos para o consumo turístico no documentário seriado Sem Reservas", de Ana Teresa Gotardo, apresentado no Congresso Internacional Comunicação e Consumo (ComuniCon2014), em São Paulo.

$92 \frac{\text { Comunicação \& Inovação, PPGCOM/USCS }}{\text { v. 17, n. } 34 \text { (92-104) maio-ago. } 2016}$ 


\section{Abstract}

This article discusses the imaginaries about slums in the city of Rio de Janeiro in the Anthony Bourdain's travel documentary series No reservations. Using a critical analysis, it is possible to realize that the episode shows UPPs and opportunities in sports, specifically in Brazilian Jiu-Jitsu, as ways to achieve a more "worthy" and "desired" life - or, from another perspective, as civilizing processes, within a context in which the slum becomes a product to be consumed, as a new tourist destination in the "divided city".

Keywords: Imaginaries. City. Consumption.

\section{Introdução}

A favela entrou no circuito turístico da cidade do Rio de Janeiro há poucos anos, desde que começou a ser "desvelada" por meio de "favelas tour", atividades normalmente voltadas para turistas estrangeiros. A ideia central era um roteiro de aventura, quase um "safari da pobreza", em que, do alto da suposta segurança de seus jipes, via-se o estranho, o diferente, o pobre. No entanto, com a necessidade de reconstrução da imagem da cidade para os megaeventos, os imaginários de medo associados ao lugar passam a ser reconstruídos para atender a uma expectativa de segurança: assim, cresce um movimento que valoriza a chegada das UPPs ${ }^{1}$ e visa à necessidade de dar oportunidades aos moradores da favela de buscar uma vida mais digna e desejável, dentro da perspectiva do olhar estrangeiro.

Este artigo baseia-se nos conceitos de Hall (2013b, p. 428) acerca da comunicação de massa: "uma estrutura produzida e sustentada através da articulação de momentos distintos, mas interligados - produção, circulação, distribuição/consumo, reprodução" -, na qual, embora autônomas, com modalidades, formas e condições de existência específicas, as etapas do processo estão conectadas e, da mesma forma, cada uma pode constituir uma ruptura. O objeto, nesse processo

é composto por significados e mensagens sob a forma de signos-veículo de um tipo específico, organizados, como qualquer forma de comunicação ou linguagem, pela operação de códigos

1 As Unidades de Polícia Pacificadora (UPPs) são uma iniciativa do Governo do Estado do Rio de Janeiro na área se segurança pública cujo início se deu em 19 de dezembro de 2008, com a instalação da primeira unidade no Morro de Santa Marta. Segundo o site do programa, as UPPs trabalham com "os princípios da polícia de proximidade, um conceito que vai além da polícia comunitária e que tem sua estratégia fundamentada na parceria entre a população e as instituições da área de segurança pública" (Fonte: <http://www.upprj.com/ index.php/o_que_e_upp>. Acesso em: 10 ago. 2014). Diversas discussões vêm sendo feitas com relação a sua atuação e eficácia. 
dentro da corrente sintagmática de um discurso. [...] O processo, desta maneira, requer, do lado da produção, seus instrumentos materiais - seus meios - bem como seus próprios conjuntos de relações sociais (de produção) - a organização e a combinação de práticas dentro dos aparatos de comunicação. Mas é sob a forma discursiva que a circulação do produto se realiza, bem como sua distribuição para diferentes audiências. Uma vez concluído, o discurso deve então ser traduzido - transformado de novo - em práticas sociais, para que o circuito ao mesmo tempo se complete e produza efeitos. Se nenhum "sentido" é apreendido, não pode haver "consumo". Se o sentido não é articulado em prática, ele não tem efeito. (Ibid., p. 429).

Quando tratamos das representações, sobre a cidade do Rio de Janeiro e sobre o carioca, produzidas por estrangeiros para exibição internacional, é necessário também compreender os imaginários envolvidos em sua produção e consumo, ou seja, quem cria os sentidos nessa produção discursiva e como o telespectador a percebe, além dos objetivos mercadológicos envolvidos - como, por exemplo, a construção de uma imagem favorável da cidade para a realização de megaeventos. Este trabalho aborda a primeira etapa do processo proposto por Hall - a produção de sentidos sobre o carioca e o Rio de Janeiro em documentários seriados sobre turismo para a TV, mais especificamente no que diz respeito à construção da favela como território a ser civilizado, sob a ótica moderna, para ser consumido como produto turístico. Será analisado o segundo bloco do episódio "Rio" do programa Sem Revervas, de Anthony Bourdain, exibido no canal TLC em 2012.

Moscovici (2007) afirma que as representações que hoje são feitas do homem urbano, da violência e das instituições que o cerca são, em boa parte, construídas ou reelaboradas pelos meios de comunicação de massa. $\mathrm{O}$ autor buscou compreender como grupos, atos e ideias constituem a sociedade. Salienta que

Nenhuma mente está livre dos efeitos de condicionamentos anteriores que lhe são impostos por suas representações, linguagem ou cultura. Nós pensamos através de uma linguagem; nós organizamos nossos pensamentos, de acordo com um sistema que está condicionado, tanto por nossas representações, como por nossa cultura. (Ibid., p. 35).

Embora Maffesoli (2004) nos alerte acerca das mudanças paradigmáticas da contemporaneidade em relação ao que chama de "pós-medievalidade" ou modernidade, é possível perceber, conforme será abordado a seguir, que a "tríade fundadora" da modernidade - composta pelo Indivíduo, a História e a Razão - está amplamente presente nos sentidos produzidos pelos meios de comunicação de massa, em especial na TV. Ainda que vejamos elementos da pós-modernidade nesses discursos (e Maffesoli destaca especialmente o retorno ao local, a importância da tribo e da montagem mitológica), a ideia de um processo civilizador, tal como 
proposto por Elias (1994), permeia todo o bloco do programa a ser analisado, construindo verdades que não levam em conta as subjetividades, mas "um elemento performático no qual o espaço favela, assim como o espaço boêmio, o espaço histórico e o espaço transgressor são empacotados como experiências a serem consumidas" (JAGUARIBE, 2011, p. 13).

\section{Processo civilizador, modernidade e representações}

Em sua obra de maior repercussão, O processo civilizador, Norbert Elias (1994) aborda, por meio de uma análise da história dos costumes durante a formação do Estado Moderno, como se deu o processo de mudança na conduta e sentimentos humanos, que, embora não tenha sido planejado, ocorreu dentro de um tipo específico de ordem. Ao se questionar como seria possível o surgimento de uma nova ordem sem que houvesse planejamento, mas que ainda assim fosse uma ordem estável e estruturada, o autor diz que

Planos e ações, impulsos emocionais e racionais de pessoas isoladas constantemente se entrelaçam de modo amistoso ou hostil. Esse tecido básico, resultante de muitos planos e ações isolados, pode dar origem a mudanças e modelos que nenhuma pessoa isolada planejou ou criou. Dessa interdependência de pessoas surge uma ordem sui generis, uma ordem mais irresistível e mais forte do que a vontade e a razão das pessoas isoladas que a compõem. É essa ordem de impulsos e anelos humanos entrelaçados, essa ordem social, que determina o curso da mudança histórica, e que subjaz ao processo civilizador. (p. 194).

O autor ilustra, de forma empírica, a dinâmica desse relacionamento, os tipos de interligações e dependência mútua entre pessoas que põem em movimento determinados processos. Aborda, assim, duas "vertentes": a social e a individual, ou seja, mudanças nos relacionamentos que modelam personalidades.

Com relação às mudanças nos relacionamentos, Elias (1994) destaca que as principais alterações que modelaram personalidades de maneira civilizadora foram: a) o processo de diferenciação social proporcionado pela competição crescente; b) a progressiva divisão de funções devido à diferenciação; c) o crescimento das cadeias de interdependência, pois o indivíduo passa a depender de um maior número de pessoas; d) a teia que se torna mais rigorosa e precisa, com ações integradas. Esse processo social compeliu o indivíduo a modelar sua conduta de forma mais diferenciada, uniforme e estável por meio do exercício do controle cada vez mais precoce, na infância; do crescimento do autocontrole consciente e inconsciente; da variação dos modelos de autocontrole de acordo com a função social e posição do indivíduo.

$\mathrm{O}$ autor ainda destaca dois processos fundamentais para a construção da civilidade: o primeiro é o que denomina de "monopolização da violência física", ou seja, quando 
o Estado passa a concentrar armas e homens armados e a defesa de uma sociedade passa a ser objeto de controle, o que "força os homens desarmados, nos espaços sociais pacificados, a controlarem sua própria violência mediante precaução ou reflexão. Em outras palavras, isso impõe às pessoas um maior ou menor grau de autocontrole" (ELIAS, 1994, p. 201); o segundo é a busca do controle da conduta no que o autor chama de "estratos agrários e urbanos inferiores" (Ibid., p. 209), ainda que haja a necessidade, por parte dos estratos mais "altos" da sociedade, de manutenção da diferenciação social.

Essa construção de que trata Elias, no entanto, está inserida dentro de um contexto da modernidade, ou "pós-medievalidade", como diz Maffesoli, autor que também destaca a importância de Elias no esclarecimento do

lento processo de "curialização" ou domesticação dos costumes que levou à constituição "do" social, isto é, de um estar-juntos singularmente mecanizado, perfeitamente previsível e essencialmente racionalizado. [...] De qualquer modo, foi justamente esse processo que regeu o nascimento de uma família cristalizada em sua estrutura nuclear, que favoreceu a "implementação do trabalho" e gerou as grandes instituições de ensino e do trabalho social, sem esquecer as da saúde e os diversos tipos de "confinamento" em que os séculos XIX e XX não foram nada avaros. Corrigindo, na medida em que isso era possível, os malefícios do devir econômico do mundo e do produtivismo que lhe era inerente, esse "social" trouxe uma segurança inegável para a grande maioria. Mas, ao mesmo tempo, e no sentido estrito do termo, "enervou" o corpo comunitário, transferindo para instâncias longínquas e abstratas a tarefa de gerir o bem comum e os liames coletivos. Tudo isso me levou a dizer que, em muitos aspectos, assistimos à instauração de uma "violência totalitária" que [...] permitiu o deslizamento de uma "solidariedade orgânica", mais próxima do cotidiano, para uma "solidariedade mecânica", promovida por uma estrutura técnica que se autoproclama avalista do bom funcionamento da vida social. (MAFFESOLI, 2004, p. 14-15).

Dentro do processo de homogeneização nacional, institucional e ideológica da modernidade encontramos, segundo o autor, uma "tríade fundadora: o Indivíduo, a História e a Razão" (Ibid., p. 17). O sujeito autônomo, que detém a si mesmo e à natureza; a História triunfal, com sua marcha para o progresso visando à evolução e a civilidade; e a Razão, uma forma da racionalidade humana que atribui valor apenas ao que é útil em sua existência e possa ser manipulado com o objetivo de "preencher as carências do indivíduo, corrigir os defeitos sociais, em suma, aperfeiçoar o que ainda existe de inacabado na natureza humana" (Ibid., p. 20).

Essas características se mostram presentes ainda hoje em diversos discursos televisivos, embora Maffesoli (2004, p. 86) nos alerte sobre as mudanças paradigmáticas em nossa sociedade: "mais que dominar o mundo, mais do que querer transformá-lo ou 
modificá-lo - atitudes que são prometeicas, todas elas - empenhamo-nos em nos unir a ele através da 'contemplação', em festejá-lo”. Mas salienta:

Convém dizer que os proprietários da sociedade - aqueles que estão em condições de falar, ou que têm o poder de fazer - foram formados por essa filosofia política, elaborada ao longo de todo o período da modernidade. Esta faz a vida social assentar-se num indivíduo racional, senhor de seus instintos, que serve de fundamento para um contrato social dirigido pela deusa Razão e criado graças a ela. (Ibid., p. 77)

Esse "poder" de falar está presente nos documentários seriados de TV sobre turismo de diversas formas, dentre as quais destaco duas. Em primeiro lugar, a visão do estrangeiro na construção da alteridade - somos esse "outro" que deve ser civilizado, ou seja, quem narra se coloca como civilizador. Também há a questão do meio, a televisão, parte das indústrias culturais que, segundo Hall (2013a, p. 281-282),

têm de fato o poder de retrabalhar e remodelar constantemente aquilo que representam; e, pela repetição e seleção, impor e implantar tais definições de nós mesmos de forma a ajustá-las mais facilmente às descrições da cultura dominante ou preferencial. [...] Essas definições não têm o poder de encampar nossas mentes; elas não atuam sobre nós como se fôssemos uma tela em branco. Contudo, elas invadem e retrabalham as contradições internas dos sentimentos e percepções das classes dominadas; elas, sim, encontram ou abrem um espaço de reconhecimento naqueles que a elas respondem. A dominação cultural tem efeitos concretos - mesmo que estes não sejam todo-poderosos ou todo-abrangentes. Afirmar que essas formas impostas não nos influenciam equivale a dizer que a cultura do povo pode existir como um enclave isolado, fora do circuito de distribuição do poder cultural e das relações de força cultural.

Por esse motivo, é importante compreender a importância dessas narrativas, já que elas não excluem conteúdos mais formais ou modernos, mas "veiculam os motivos perenes da ordem inacabada a que o ser civilizado atribui uma confiança mal definida: o medo do estrangeiro, a magia dos lugares, o abandono surrealista ao espaço urbano, a viagem iniciática” (MAFFESOLI, 2004, p. 155).

\section{As UPPs e o esporte como processos civilizadores}

A visita de Anthony Bourdain à Rocinha é realizada alguns meses após a introdução da UPP na comunidade, no início de 2012. Na estrutura narrativa do episódio, há um bloco dedicado somente a ela, separando-a do Rio de Janeiro das praias e das paisagens 
paradisíacas que dominam a proposta turística, e corroborando a ideia de "cidade dividida" citada pelo apresentador. Sua descrição a apresenta como

a maior das favelas do Rio. Basicamente, morros [moutainous shantytown] que normalmente não estariam nos roteiros turísticos tradicionais. Até recentemente, não policiada, desesperadamente pobre, a outra parte do que é chamada "a cidade dividida". Governada pelo erro, pela arma, por forças coercitivas, por traficantes poderosos. (ANTHONY BOURDAIN, 2012, tradução nossa).

A forma como a favela é apresentada reforça o imaginário social da violência, abandono e medo. Em oposição ao restante do episódio, a bossa nova já não domina os fundos musicais - ela é substituída por trilhas que sugerem medo e tristeza, inclusive quando se trata da paisagem sonora. A beleza da paisagem visual é substituída por vielas estreitas, lajes, casas com furos de bala e sem emboço, fiação elétrica desordenada, policiais fortemente armados, entre outros, mas ela volta à tona quando Anthony (Tony) menciona o abismo entre ricos e pobres existente no Brasil, de modo a reiterar o contraste.

$\mathrm{O}$ apresentador conta com a presença de um mediador para a apresentação da Rocinha: um morador da favela chamado Paulo Amendoim, descrito pelo apresentador como "um guia turístico, com algo de flerte, prefeito não oficial da vizinhança que também possui certo senso de humor". Trata-se de uma tentativa de apresentação de um "malandro", associado a um suposto samba como fundo musical (suposto por se tratar de um esforço estrangeiro de recriar um samba reconhecível internacionalmente) e a uma brincadeira com Tony: Paulo pede para que o apresentador tome um líquido para apenas depois contar a ele o que seria - um "viagra natural" feito com ingredientes brasileiros. "Você não vai dormir por uma semana", diz o guia. Salienta-se que é comum ver nesse tipo de programa a busca pela competência cultural de um mediador, a qual, de acordo com Martín-Barbero (2003, p. 304), é um "dos lugares dos quais provêm as construções que delimitam e configuram a materialidade social e a expressividade cultural da televisão". Os personagens brasileiros utilizados no documentário podem ser considerados peças fundamentais na mediação "entre as lógicas do sistema produtivo e as do sistema de consumo, entre a do formato e a dos modos de ler, dos usos" (Ibid., p. 311). Sobre Paulo Amendoim, nota-se, ainda, como a figura desse mediador, morador da favela, negro e pobre, parte de "centenas de milhares" de pessoas que "nascem sem perspectiva" (segundo o episódio), é uma pessoa descontraída e alegre, contrastando com outros personagens e com a estrutura narrativa do episódio.

Tony menciona que "as coisas começaram a mudar quando o governo do estado do Rio iniciou uma nova aproximação" e Paulo ratifica: "não há mais gangues. Eles não têm mais o poder que tinham antes". Apresentado também como ativista, o mediador 
menciona as mudanças ocorridas na comunidade: "não havia água ou eletricidade na Rocinha, mas hoje, embora pareça desorganizado [e mostra um poste cheio de ligações elétricas em um emaranhado de fios], tudo funciona". Paulo diz: "não foi fácil. Nós tivemos que protestar na rua, fechar a rua, para que o governo nos visse". Tony informa, então, que "o governo investiu US\$1,7 bilhão em água, sanitização e moradia, fornecendo, pela primeira vez, infraestrutura a comunidades de centenas de milhares que não existem oficialmente". Embora a narração seja motivadora, as imagens ainda fortalecem a ideia um lugar ainda muito precário, onde há muito o que fazer.

Tony chama a atenção para o fato de que há policiamento na comunidade, e pergunta se há 10 anos também havia. Paulo então diz que o policiamento chegou apenas em novembro (embora não saibamos a data de gravação, a forma como ele fala dá a entender que o policiamento chegou há poucos meses, o que, inclusive, assusta Tony) e agora eles tinham "pacificação". O apresentador explica o processo de pacificação, que removeu os traficantes e levou a presença da polícia à comunidade, mas o fundo musical que sugere medo, associado à imagem dos policiais fortemente armados, deixa dúvidas sobre essa suposta "paz". O apresentador vivencia, então, uma ação da polícia, e o clima de medo toma conta do episódio. A música de fundo silencia e a paisagem sonora surge: barulhos de tiros são ouvidos. Tony, aparentando um pouco mais de tranquilidade (aparentemente algum tempo depois) após ter passado por um momento de forte emoção aventureira, informa que "a ação da polícia que vimos foi exibida no noticiário. Atiraram em um homem no ombro".

Pode-se notar nessas passagens a importância dada à presença do governo do estado e de sua polícia, relacionando-a diretamente às "melhorias" ocorridas nos últimos anos na comunidade. A ideia de uma instituição, de um poder centralizado, somada à monopolização da força e violência físicas, destaca-se tal como proposto por Elias (1994), como parte de um processo civilizador moderno. E, embora o autor tenha analisado esse processo na formação das cortes europeias ("a nobreza belicosa é substituída por uma nobreza domada, com emoções abrandadas"), com a transformação de guerreiros em cortesãos, é possível perceber as similaridades do estudo com as representações do episódio em questão, na busca de uma conduta voltada para a regulação, para a "civilidade". Num lugar representado pelo contraste social, cabe - dentro da ordem utilitária moderna e da economia do consumo turístico - diminuir o abismo dos costumes, do vestuário, da variedade de vida.

O apresentador e Paulo almoçam na Barraca Nordestina, lugar onde "as pessoas da vizinhança costumam fazer refeições". Algumas crianças os acompanham. Paulo diz: “comida do Nordeste". E Tony pergunta: "de qual lugar do Nordeste?". "Fortaleza", 
responde Paulo. Tony então afirma: "muitas pessoas que moram aqui vieram de outros lugares, certo?". Paulo concorda enquanto continua a comer o prato composto por arroz, feijão, vegetais, pé de galinha e uma pimenta "quente" acondicionada em uma garrafa PET. É interessante notar, nessa passagem, o destaque para o não-carioca, em contraste com o que seria o "verdadeiro" carioca: aquele apresentado no primeiro bloco, o da praia. Não se trata apenas de especificar o local de nascimento, trata-se de delimitar a "carioquicidade" de acordo com a forma e estilo de vida, para além do lugar da cidade onde se vive. Também se destacam suas diferenças físicas: enquanto o carioca da praia é elogiado por seu corpo (jovem, malhado, depilado e branco), na favela exibem-se crianças, negros, pessoas gordas, excluídos do primeiro bloco, todos aqueles que, por não se encaixarem, são "outros".

Para finalizar a visita de Tony à Rocinha, Paulo o leva até sua casa ("eu moro perto do céu porque, quando eu morrer, a viagem será mais curta"), onde, da laje, vê-se o contraste da "cidade dividida" - favela em primeiro plano, seguida de prédios altos e luxuosos, com a Pedra da Gávea ao fundo - e se faz a primeira menção de uma "salvação" para as crianças do morro: brincar, empinar pipa. O apresentador explica: "empinar e cortar pipas (kitefighting) são uma forma barata e popular de entretenimento para crianças que têm muito pouco". "Você não vê o céu, só pipas", diz Paulo. Tony continua: "com um pouco de prática, esses garotos desenvolvem um nível incrível de controle", mencionando, também, o vidro usado no cerol para aparar a pipa, o que pode causar mortes. Música triste e pés descalços no concreto sugerem que essas pessoas precisam de piedade e ajuda. Tony tenta participar da brincadeira, mas deixa a pipa cair - é então que Paulo mostra sua destreza e a levanta, como se empinar pipa não fosse "coisa para gringo" - e Tony não acredita que seu guia "salva" a brincadeira. Paulo diz que não há idade para soltar pipa, pois é relaxante. Segundo ele, "você fica na laje e brinca. Mas, ao redor, nós temos muitas coisas: veja o verde, o cenário, a grande pedra e a floresta também, Floresta da Tijuca". E então o apresentador narra: "como eu disse, você cresce pobre nessa vizinhança, como outros milhares no país, você tem que trabalhar muito duro para conseguir qualquer lugar bom na vida" - o que leva a entender que aquele não é um lugar bom, desejável, e que o trabalho é a solução para uma vida melhor. Paulo então conclui com um pensamento: "a melhor coisa que você pode mostrar a essas crianças é empinar pipa”.

Mas Tony tem outra sugestão: a cena seguinte mostra um grupo de crianças no Instituto Kapacidade, organização criada pela família Gracie para ensinar a "orgulhosa tradição do jiu-jitsu brasileiro" a crianças em situação de vulnerabilidade social. Tony diz que, assim como o futebol, o jiu-jitsu é um "esporte nacional". Ele afirma que não 
se trata de uma luta de rua, algo agressivo em si, mas de usar a força do oponente contra ele próprio. Tony apresenta ao telespectador a história do jiu-jitsu:

em 1914, Mitsuyo Maeda, um mestre japonês de jiu-jitsu, emigrou para o Brasil, onde se tornou amigo de Gastão Gracie, um empresário que o ajudou a se estabelecer. Para mostrar sua gratidão, o mestre se ofereceu para ensinar jiu-jitsu ao filho de Gastão. Em suas mãos, a arte foi modificada, tornando-se o que é hoje: uma disciplina que enfatiza a técnica e o tempo. Os Gracie formam a primeira família do jiu-jitsu brasileiro.

Em meio a crianças fazendo exercícios e a demonstrações de golpes por professores a alunos, Tony apresenta Igor, sobrinho-neto de Gastão, treinador de Ottavia (esposa do apresentador que vem ao Rio de Janeiro para participar de uma luta de jiu-jitsu, a qual constitui parte da estrutura narrativa do episódio) e mediador nessa etapa do programa. Igor representa o instituto, criado por sua irmã - campeã mundial e uma das primeiras mulheres faixas-pretas no esporte -, que decidiu fazer algo pelas crianças das favelas do Rio. O brasileiro diz:

eles [as pessoas da equipe do instituto] os alimentam, as crianças ganham café da manhã e almoço antes de irem à escola. Eles têm tutoria, têm que ter boas notas. Eles têm que se comportar na escola. Nós não queremos ensinar uma arte marcial. Nós queremos ensinar a eles como respeitar o outro. Um estilo de vida. Uma nova criança entra e os mais velhos o ajudam. Eles não praticam bullying. De onde eles vêm, eles sofrem muito bullying. Esses garotos já viram coisas que você jamais imaginaria.

O apresentador fala, em tom alegre, que "é ótimo ver as crianças, tipo, quando as crianças fazem um movimento, e depois saem, elas têm um grande sorriso no rosto". Igor salienta que, devido à falta de fundos, não pode atender mais crianças (na ocasião da gravação, atendia de 100 a 150) e que há uma lista de espera de mais de 200 pessoas. Tony parece chocado com isso - e assim termina o bloco, com o que seria a alternativa a uma vida de miséria e violência, que não pode ser levada adiante devido à falta de dinheiro.

Também nessa parte do episódio podemos inferir que há uma ideia do esporte como "processo civilizador", no sentido proposto por Elias: com o desejo, de uma classe mais abastada, de assimilação, por parte das classes mais baixas, do que seria considerado um "bom modo de vida". Essa noção de "bom modo de vida" é construída desde a apresentação do jiu-jitsu e sua história, com seu desenvolvimento na família Gracie como ajuda ao próximo e gratidão, passando pela questão da arte como técnica, tempo e uso da força do oponente contra ele mesmo, até chegar ao objetivo do Instituto Kapacidade: 
ensinar respeito ao outro como estilo de vida. As imagens também mostram as relações entre mestres e alunos, e afirmam uma ideia de "escola" como instituição formadora de cidadãos aptos para o trabalho e a mudança de vida que devem almejar.

\section{Considerações finais}

Esta análise se insere dentro de um projeto mais amplo que objetiva compreender as representações do Rio de Janeiro e do carioca em documentários seriados estrangeiros sobre o turismo produzidos para exibição na televisão internacional. Nesse projeto, partimos da hipótese de que há uma mudança, a partir de 2008, na forma como a cidade é representada, como parte de um projeto de branding que visa a colocar o Rio de Janeiro no centro do turismo internacional e da realização de megaeventos por meio de sua construção como "cidade ideal", sob a ótica moderna. Jaguaribe (2011, p. 3-4) diz que

O crucial no processo de branding é vender uma imagem da cidade para que ela possa ser a recipiente de recursos, investimentos, turismo e ganhos econômicos. Cada cidade terá que inventar e apostar nas suas próprias estratégias de branding levando em conta uma adequação entre seus repertórios e seus slogans. No caso do Rio de Janeiro, famosamente alcunhada de "cidade maravilhosa", a busca pelo branding convidativo se defronta com legados contraditórios.

Nesse sentido, o contraste social e a violência das favelas, ícones no imaginário global, passam a ser reinventados para produzir "a segurança da expectativa preenchida" (Ibid., p. 6). Essa reinvenção passa por um ideal civilizatório moderno, constrói contextos de alteridade e cria mapas nacionais que não levam em conta as subjetividades, mas que representam um projeto político, muitas vezes arbitrário, de transformar o Rio de Janeiro na capital da nova cartografia pós-nacional fundada por tentativas de organizar a vida social em torno do turismo (APPADURAI, 1997).

Amancio (2000, p. 70), em sua pesquisa sobre as representações do brasileiro no cinema de ficção estrangeiro, salienta que, tal como podemos ver na TV,

Há sempre um estrangeiro na trama para estabelecer os limites e a prerrogativa de um determinado ponto de vista, de um recorte que se explicita nas representações da alteridade. Colocar na tela um outro povo é tarefa que exige uma negociação narrativa, plástica, sonora. Mesmo o 
documentário, campo maior da evidência da "verdade" na tradição cinematográfica, recorre a intermediações dessa natureza na representação do Outro.

Certeau (1998, p. 40) alerta para o fato de que "a presença e a circulação de uma representação (ensinada como o código da promoção socioeconômica por pregadores, por educadores ou por vulgarizadores) não indicam de modo algum o que ela é para seus usuários”. Nesse mesmo sentido, Maia e Lattanzi (2007, p. 75) observam que

É no espaço cotidiano e construído na horizontalidade onde se operam as negociações e os jogos de forças que resistem às imposições dos processos homogeneizantes gerados nos espaços verticais. Nestes espaços verticais estão presentes as empresas com seus grandes negócios, o mundo do direito, os homens que supostamente seriam poderosos e os gerenciamentos objetivos do tempo da produção. O exercício da contrarracionalidade serve para resistir aos processos "globalitários", mesmo aqueles oriundos de países que se consideravam centrais durante a modernidade.

Mas "viver" o cotidiano dessas representações para compreender a dimensão do lugar, o imaginário de seus moradores sobre ele e o espaço concreto de atividades talvez não seja possível para a maior parte desses telespectadores ao redor do mundo. É importante, por isso, ouvir o alerta de Moscovici (2007): mesmo que pareçam realidades inquestionáveis, é necessário confrontar as representações para que elas não acabem por limitar todo um rol de cenários, práticas e subjetividades a estereótipos comercializáveis. É necessário resgatar esses discursos para percebê-los e desconstruí-los, de modo a olhar criticamente para essas representações e entender seus contextos sociais, econômicos e políticos, bem como a importância do consumo turístico e para a definição/compreensão da cidade.

\section{Referências}

AMANCIO, T. O Brasil dos gringos: imagens no cinema. Niterói: Intertexto, 2000.

ANTHONY BOURDAIN: No Reservations. Episódio: Rio. 8. Temporada. Apresentador: Anthony Bourdain. Silver Spring: Travel Channel, 15 out. 2012.

APPADURAI, A. Soberania sem territorialidade. Novos Estudos, n. 49, p. 33-46, nov. 1997.

DE CERTEAU, M. A invenção do cotidiano: artes de fazer. Petrópolis: Vozes, 1998.

ELIAS, N. O processo civilizador. Rio de Janeiro: Jorge Zahar, 1994.

HALL, S. Notas sobre a desconstrução do "popular”. In: SOVIK, L. Da diáspora: identidades e mediações culturais. Belo Horizonte: Editora da UFMG, 2013a. p. 274-292.

. Codificação/decodificação. In: SOVIK, L. Da diáspora: identidades e mediações culturais. Belo Horizonte: UFMG, 2013b. p. 428-447. 
JAGUARIBE, B. Imaginando a Cidade Maravilhosa: modernidade, espetáculo e espaços urbanos. In: COMPÓS, 20., 2011, Porto Alegre. Anais... Porto Alegre: Associação Nacional dos Programas de Pós-Graduação em Comunicação, 2011. Disponível em: <http://www.compos.org.br/data/biblioteca_1694.doc>. Acesso em: 9 fev. 2014.

MAIA, J.; LATTANZI, A. Territórios de criatividade. Revista FAMECOS, Porto Alegre, n. 33, p. 73-78, ago. 2007. MAFFESOLI, M. Notas sobre a pós-modernidade: o lugar faz o elo. Rio de Janeiro: Atlântica, 2004.

MARTÍN-BARBERO, J. Dos meios às mediações: comunicação, cultura e hegemonia. Rio de Janeiro: UFRJ, 2003.

MOSCOVICI, S. Representações sociais: investigações em psicologia social. Petrópolis: Vozes, 2007. 